\title{
Evaluation of the TEST 1 erythrocyte sedimentation rate system and intra- and inter-laboratory quality control using new latex control materials
}

\author{
Choong-Hwan Cha ${ }^{2, a}$, Young Joo Cha ${ }^{1, *}$, Chan- \\ Jeoung Park ${ }^{2, *}$, Hyun Kyung Kim³ ${ }^{3}$ Eun-Jong Cha ${ }^{4}$, \\ Duck Hee Kim², Honghoon², Jae-Seol Jung ${ }^{3}$, \\ Mi-Jung Kim², Seongsoo Jang ${ }^{2}$, Hyun-Sook Chi \\ and Dong Soon $\mathrm{Lee}^{3}$ \\ ${ }^{1}$ Department of Laboratory Medicine, Chung-Ang \\ University College of Medicine, Seoul, Korea \\ ${ }^{2}$ Department of Laboratory Medicine, University of \\ Ulsan College of Medicine and Asan Medical Center, \\ Seoul, Korea \\ ${ }^{3}$ Department of Laboratory Medicine, Seoul National \\ University College of Medicine, Seoul, Korea \\ ${ }^{4}$ Department of Biomedical Engineering, School of \\ Medicine, Chungbuk National University, Cheongju, Korea
}

[coefficients of variation (CV) 6.6\%-21.7\%] with patient samples and inter-assay precision (CV $0.0 \%-6.8 \%)$ with latex control materials were satisfactory. The reference ranges of 2-10 mm/h for males and $2-19 \mathrm{~mm} / \mathrm{h}$ for females were established. Inter-laboratory QC data with latex control materials in three hospitals demonstrated good accuracy and satisfactory precision (CV $0.0 \%-14.4 \%$ ).

Conclusions: Our results demonstrate that the TEST 1 QC is reliable and the latex control materials are valuable for inter-laboratory proficiency testing.

Clin Chem Lab Med 2010;48:1043-8.

Keywords: erythrocyte sedimentation rate; latex control; quality control; TEST 1.

\section{Introduction}

The erythrocyte sedimentation rate (ESR) is widely used in clinical practice as an indicator of inflammation, infection, trauma, or malignant disease (1). The current reference method for measurement of ESR is that proposed by Westergren; the sedimentation of red blood cells is measured by observing the level to which cells fall in a given time interval, usually $1 \mathrm{~h}$, in a well-described, specific pipette (2). An automated measurement procedure, the TEST 1 (Alifax, Padova, Italy) has been marketed. This system allows automatic measurement of ESR in specimens collected in both sodium citrate and EDTA blood sample tubes using a microagglutination method (3).

ESR performed using manual and semi-automated methods has long been considered as a simple procedure that could be performed without the need for quality control (QC) (4). In clinical laboratories, reliable methods for calibration and the use of appropriate control materials are required for monitoring the accuracy and precision of any routine method. In the last few years, a number of commercial QC materials have appeared on the market, but most are based on stabilized whole blood and are not suitable for use with techniques involving autoanalyzers, such as the TEST 1 that evaluates the kinetics of the aggregation reaction $(1,5)$. Recently, a new latex control material has been developed to increase instrument reliability and to enable the performance of statistical QC (6).

The goal of this study was to evaluate ESR measurement using the TEST 1 system and to investigate QC procedures 
based on the use of latex control materials for the daily intraand inter-laboratory QC of ESR in the clinical laboratory.

\section{Materials and methods}

\section{Materials}

All blood for the study was collected in 3-mL tripotassium ethylenediaminetetraacetic acid ( $\mathrm{K}_{3}$ EDTA) tubes (Becton Dickinson, Franklin Lakes, NJ, USA). Blood samples were obtained from hospitalized and ambulatory patients at three tertiary care hospitals (Hospital A: Seoul National University Hospital, Seoul, Korea; Hospital B: Chung-Ang University Hospital, Seoul, Korea; Hospital C: University of Ulsan College of Medicine and Asan Medical Center, Seoul, Korea), and processed for analysis. All samples were obtained under standardized conditions, in the morning after a night of fasting, and tested within $4 \mathrm{~h}$ of venipuncture, according to the recommendations of the International Council for Standardization in Haematology (ICSH) (7).

\section{Westergren method}

The Westergren method was performed according to ICSH specifications on undiluted blood anticoagulated with EDTA using glass pipettes (Greiner Bio-One GmbH, Kremsmuenster, Austria) (7). During sedimentation, pipettes were mounted vertically on appropriate supporting racks and kept at room temperature $\left(21-22^{\circ} \mathrm{C}\right)$.

\section{TEST 1 method}

TEST 1 is a closed automated analyzer that determines ESR at $37^{\circ} \mathrm{C}$ by assessment of red cell aggregation. A $150 \mu \mathrm{L}$ blood sample is delivered into a capillary tube. The electrical signal, collected by a photodiode detector, is directly correlated to red cell aggregation in the capillary. A mathematical algorithm converts the raw data obtained from optical density signals into ESR results, which are transformed into comparable Westergren values. The first result is obtained in about 4 min and subsequent results are obtained every
$20 \mathrm{~s}(1,3,6,8)$. The most recent version of TEST 1 , the TEST 1 THL, includes a new version of the software that allows the analyzer to run the new latex controls. The TEST 1 THL analyzers were set up in the laboratories of the three hospitals.

\section{Latex calibrators and control materials}

The calibrators and control materials for the TEST 1 are ready-made turbidimetric standards of synthetic latex solutions. Each set is composed of three tubes each containing $3 \mathrm{~mL}$ of latex solution at three different concentrations (6). Each QC level has a known turbidity value, on which the instrument performs transmittance measurements correlated to the ESR value. The TEST 1 analyzers were calibrated using the newly developed calibrators.

\section{Accuracy}

We selected 184 blood samples from the patients of hospital A for comparison studies. All had TEST 1 ESR values ranging from 5 to $105 \mathrm{~mm} / \mathrm{h}$ and grouped into one of 10 classes on the basis of the TEST 1 ESR value. The Westergren ESR values were obtained at hospital A. Each residual sample was transported, under cold storage, to hospital B. In hospital B, the samples were returned to room temperature for $45 \mathrm{~min}$ and remixed before the measurement of ESR by TEST 1 . Each residual sample was transported, again in the cold, to hospital $\mathrm{C}$, where the same procedures as those in hospital $\mathrm{B}$ were performed. In samples with hematocrit $(\mathrm{Hct}) \leq 35 \%$, ESR values were corrected to a Hct of $40 \%$ using Fabry's formula: corrected Westergren $\mathrm{ESR}$ value $=($ Westergren $\mathrm{ESR} \times 15 \%) /(55 \%-\mathrm{Hct} \%)(9)$.

\section{Precision}

A reproducibility study was performed at hospital B using blood samples and three levels of latex controls. To test intra-assay precision, 20 blood samples, stored at room temperature and with TEST 1 ESR values of more than $5 \mathrm{~mm} / \mathrm{h}$, were used. Eight replicate measurements of 10 blood samples with different ESR ranges were performed under continuous loading, and nine replicate measurements of another 10 blood samples were made at 30 min intervals.

Table 1 Correlation and differences between TEST $1^{\mathrm{a}}$ and Westergren ESR values.

\begin{tabular}{|c|c|c|c|c|}
\hline Method & $\mathrm{R}^{2}$ & Difference & Limit of agreement & $95 \% \mathrm{CI}$ \\
\hline \multicolumn{5}{|l|}{ Overall, $\mathrm{n}=184$} \\
\hline Westergren - TEST 1 A & 0.70 & 21.6 & -18.6 to 61.8 & 18.6 to 24.6 \\
\hline Westergren - TEST 1 B & 0.72 & 17.0 & -22.5 to 56.5 & 14.1 to 19.9 \\
\hline Westergren - TEST $1 \mathrm{C}$ & 0.72 & 30.8 & -9.7 to 71.4 & 27.8 to 33.9 \\
\hline Corrected Westergren - TEST 1 A & 0.63 & 4.6 & -34.0 to 43.2 & 1.7 to 7.4 \\
\hline Corrected Westergren - TEST 1 B & 0.67 & -0.0 & -40.9 to 40.8 & -3.1 to 3.0 \\
\hline Corrected Westergren - TEST $1 \mathrm{C}$ & 0.65 & 13.8 & -20.2 to 47.9 & 11.3 to 16.4 \\
\hline \multicolumn{5}{|l|}{ Hct $\leq 35 \%, \mathrm{n}=95$} \\
\hline Westergren - TEST 1 A & 0.63 & 29.4 & -11.4 to 70.3 & 25.2 to 33.7 \\
\hline Westergren - TEST 1 B & 0.66 & 24.7 & -17.4 to 66.8 & 20.3 to 29.1 \\
\hline Westergren - TEST $1 \mathrm{C}$ & 0.66 & 40.3 & 1.5 to 79.1 & 36.3 to 44.3 \\
\hline Corrected Westergren - TEST 1 A & 0.66 & -3.5 & -40.9 to 33.8 & -7.4 to 0.4 \\
\hline Corrected Westergren - TEST $1 \mathrm{~B}$ & 0.72 & -8.3 & -52.0 to 35.4 & -12.8 to -3.7 \\
\hline Corrected Westergren - TEST $1 \mathrm{C}$ & 0.70 & 7.3 & -23.3 to 38.0 & 4.1 to 10.5 \\
\hline \multicolumn{5}{|l|}{ Het $>35 \%, \mathrm{n}=89$} \\
\hline Westergren - TEST 1 A & 0.79 & 13.2 & -19.2 to 45.6 & 9.7 to 16.7 \\
\hline Westergren - TEST 1 B & 0.83 & 8.8 & -20.3 to 37.9 & 5.7 to 11.9 \\
\hline Westergren - TEST $1 \mathrm{C}$ & 0.83 & 20.8 & -11.5 to 53.1 & 17.3 to 24.2 \\
\hline
\end{tabular}

aTEST 1 ESR values measured at hospital A, B, or C. CI, confidence interval. 
The inter-assay precision of three levels of control material was evaluated over 5 days, with five determinations per day.

\section{Stability test}

A stability test was performed at hospital C. The stability of ESR samples over time was evaluated by storing the 184 blood specimens used in the accuracy study for $24 \mathrm{~h}$ at $4^{\circ} \mathrm{C}$. The samples were returned to room temperature for $45 \mathrm{~min}$, remixed and then remeasured.

\section{Reference range}

The reference range was established at hospital $\mathrm{C}$ using blood samples collected from 220 healthy individuals (110 males and 110 females) visiting the health promotion center at hospital C. To calculate the reference range, and considering the increase in ESR in relation to age, ESR values were evaluated separately for each decade of adult life in men and women.

\section{Inter-laboratory QC with latex control materials in three hospitals}

ESR measurements of three levels of latex control materials were performed over 11-16 days, with one determination per day, in each of three hospitals.

\section{Statistical analysis}

Statistical analysis was carried out using MS Excel 2003 software (Microsoft, Seattle, WA, USA), SPSS version 13.0 software (SPSS Inc., Chicago, IL, USA), and MedCalc version 11.1.1.0 (MedCalc, Mariakerke, Belgium). The data from the method comparison studies were analyzed using Passing-Bablok regression, non-linear regression and Bland-Altman analysis. To estimate precision, we computed means, SDs, and coefficients of variation (CVs). Differences between means for stability were evaluated by the paired Student's t-test. Estimates for the reference range were based on a non-parametric statistical method using percentiles. Comparison of means between genders in any given age group was performed using the Mann-Whitney test. Comparison of means between agerelated groups in the male or female reference population was achieved by the Kruskal-Wallis test. Statistical significance was considered if $\mathrm{p}<0.05$.

\section{Results}

\section{Accuracy}

There was statistically significant correlation between the TEST 1 and Westergren data $(\mathrm{p}<0.001)$, but notable differences were noted also (Table 1 and Figure 1). PassingBablok regression showed a non-linear relationship between both methods. The TEST 1 ESR values were lower than the Westergren values. The differences between TEST 1 and Westergren values in 89 blood samples with Hct $>35 \%$ were smaller than those in 95 blood samples with Hct $\leq 35 \%$. In addition, the correlation coefficients between both methods in samples with Hct $>35 \%$ were higher than those in samples with Hct $\leq 35 \%$. The differences between TEST 1 and corrected Westergren values were smaller than differences between TEST 1 and non-corrected Westergren values.

\section{Precision}

Intra-assay reproducibility using blood samples over a wide range of ESR values is shown in Table 2A. Continuous loading revealed good precision except in the lowest and highest ranges, but loading at intervals of $30 \mathrm{~min}$ (with a total duration of measurement of more than $4 \mathrm{~h}$ and $30 \mathrm{~min}$ ) showed a higher CV compared with continuous loading.

Inter-assay reproducibility using latex control materials is shown in Table 2B. The level 1 control encompasses ESR values in the normal population and levels 2 and 3 encompass the clinically significant ESR ranges. The precision of the three levels of control materials was very good.

\section{Stability test}

Storage of blood samples at $4^{\circ} \mathrm{C}$ for up to $24 \mathrm{~h}$ caused a significant decrease in ESR values measured with the TEST 1
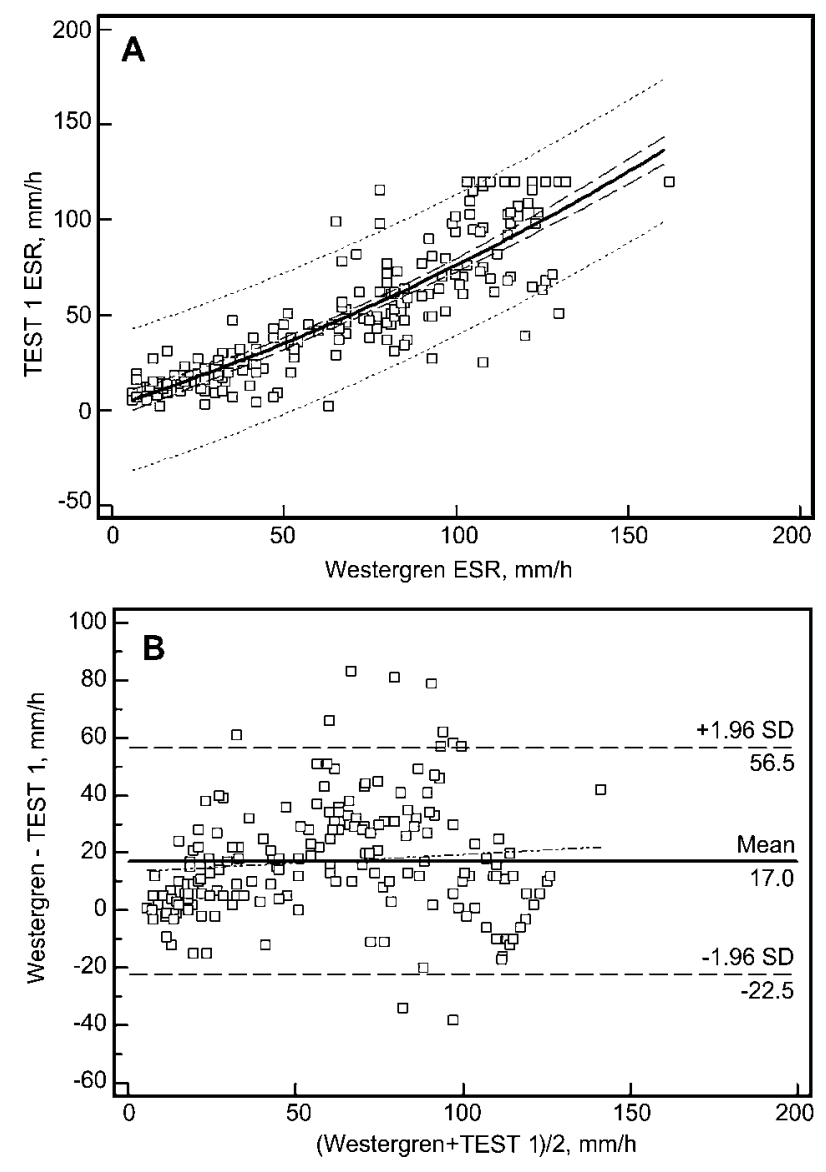

Figure 1 Comparison of TEST 1 and Westergren methods for ESR measurements using data obtained from hospital B.

(A) Scattergram of correlations between the ESR measurement methods $\left(n=184 ; \quad y=0.001608 x^{2}+0.5823 x+1.9242 ; \quad R^{2}=0.72\right.$; $\mathrm{p}<0.001$ ). The solid line indicates regression line and the dashed lines indicate $95 \%$ confidence interval for the regression line and the dotted lines indicate $95 \%$ prediction interval for the regression line. (B) Plot of differences between the ESR measurement methods. Horizontal dashed lines denote the limits of agreement and oblique dotted line denotes regression line of differences vs. averages. 
Table 2 Intra-assay (A) and inter-assay (B) reproducibility of TEST 1 for measurement of ESR.

\begin{tabular}{|c|c|c|c|c|c|c|c|c|c|}
\hline \multicolumn{5}{|c|}{ (A) Intra-assay, blood samples } & \multicolumn{5}{|c|}{ (B) Inter-assay, quality control materials, $\mathrm{n}=25^{\mathrm{a}}$} \\
\hline \multirow[t]{2}{*}{$\begin{array}{l}\mathrm{ESR}, \\
\mathrm{mm} / \mathrm{h}\end{array}$} & \multicolumn{2}{|c|}{$\begin{array}{l}\text { Continuous loading } \\
\mathrm{n}=8\end{array}$} & \multicolumn{2}{|c|}{$\begin{array}{l}\text { 30-min interval } \\
\mathrm{n}=9\end{array}$} & \multirow[t]{2}{*}{ ESR } & \multirow[t]{2}{*}{$\begin{array}{l}\text { Mean } \pm S D \\
\mathrm{~mm} / \mathrm{h}\end{array}$} & \multirow[t]{2}{*}{$\mathrm{CV}, \%$} & \multirow[t]{2}{*}{$\begin{array}{l}\text { Claimed } \\
\text { values }\end{array}$} & \multirow[t]{2}{*}{ Bias, \% } \\
\hline & $\begin{array}{l}\text { Mean } \pm S D \\
\mathrm{~mm} / \mathrm{h}\end{array}$ & $\mathrm{CV}, \%$ & $\begin{array}{l}\text { Mean } \pm \mathrm{SD}, \\
\mathrm{mm} / \mathrm{h}\end{array}$ & $\mathrm{CV}, \%$ & & & & & \\
\hline $5-10$ & $5.5 \pm 1.2$ & 21.7 & $7.2 \pm 1.1$ & 15.1 & Level 1 & $4.9 \pm 0.3$ & 6.8 & $5(4-6)$ & -2.0 \\
\hline $11-20$ & $13.5 \pm 1.3$ & 9.7 & $17.4 \pm 2.0$ & 11.5 & Level 2 & $24.0 \pm 0.0$ & 0.0 & $23(20-26)$ & 4.3 \\
\hline $21-30$ & $24.9 \pm 1.6$ & 6.6 & $25.7 \pm 3.7$ & 14.3 & Level 3 & $64.9 \pm 0.6$ & 0.9 & $63(54-72)$ & 3.0 \\
\hline $31-40$ & $37.4 \pm 3.6$ & 9.7 & $34.1 \pm 4.0$ & 11.8 & & & & & \\
\hline $41-50$ & $45.5 \pm 2.3$ & 5.1 & $48.0 \pm 3.7$ & 7.7 & & & & & \\
\hline $51-60$ & $58.9 \pm 4.6$ & 7.8 & $53.6 \pm 5.3^{\mathrm{b}}$ & 9.9 & & & & & \\
\hline $61-70$ & $78.4 \pm 7.0$ & 8.9 & $74.3 \pm 7.8$ & 10.5 & & & & & \\
\hline $71-80$ & $74.7 \pm 6.0^{\mathrm{b}}$ & 8.0 & $68.8 \pm 6.1$ & 8.8 & & & & & \\
\hline $81-90$ & $84.4 \pm 6.6$ & 7.8 & $74.1 \pm 7.1$ & 9.6 & & & & & \\
\hline$>90$ & $108.9 \pm 13.5^{\mathrm{b}}$ & 12.4 & $116.6 \pm 9.2$ & 7.9 & & & & & \\
\hline
\end{tabular}

${ }^{\mathrm{a}}$ Five different days, five determinations per day. ${ }^{\mathrm{b}}$ Seven replicates.

(Figure 2). The mean difference was $6.05 \mathrm{~mm} / \mathrm{h}(95 \%$ confidence interval 5.067-7.031, $\mathrm{p}<0.0001$ ), reflecting a decrease of $18.7 \%$. The difference increased in proportion to ESR values.

\section{Reference range}

The reference range for males was $2-10 \mathrm{~mm} / \mathrm{h}$, and that for females 2-19 mm/h (Table 3 ). There were significant differences between the genders in groups aged 60 years or less $(\mathrm{p}=0.028, \quad 0.002,0.002$, and 0.001 for groups aged 18-30 years, 31-40 years, 41-50 years, and 51-60 years, respectively). There was no significant difference between the genders in the group aged over 60 years $(p=0.144)$. No significant differences were seen among age-related groups in both the male and female reference population $(p=0.562$, $\mathrm{p}=0.652$ ).

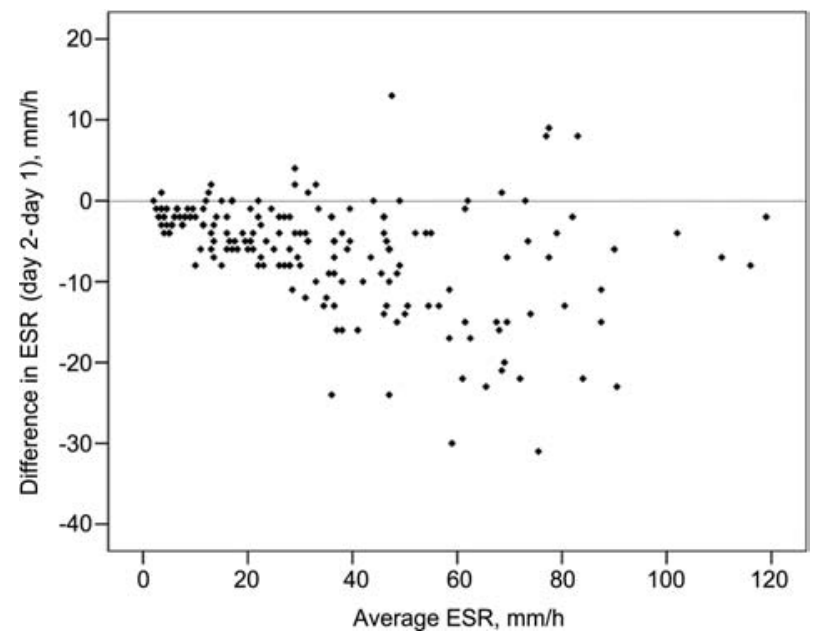

Figure 2 Stability of ESR samples after storage for $24 \mathrm{~h}$ at $4^{\circ} \mathrm{C}$ $(\mathrm{n}=184)$.

The mean difference was $6.05 \mathrm{~mm} / \mathrm{h}(\mathrm{p}<0.0001)$.

\section{Inter-laboratory QC using latex control materials in three hospitals}

Accuracy and reproducibility of the latex control materials used for QC are shown in Table 4. All three hospitals demonstrated good accuracy and satisfactory precision, even with level $1 \mathrm{QC}$.

\section{Discussion}

We evaluated the TEST 1 system and investigated QC procedures using newly developed latex control materials. The TEST 1 system showed good correlation with the Westergren method and satisfactory precision. The latex control materials showed good accuracy and suitable precision for the daily intra- and inter-laboratory QC of ESR. The proposed newly developed turbidimetric standards are available, easy to use, commutable with human whole blood samples, and the costs are comparable to those of other commercially available control materials (6).

We found that Westergren ESR values were higher than those obtained using TEST 1, especially in samples with Hct $\leq 35 \%$. It has been suggested that the Westergren method overestimates ESR in samples of low Hct (8). Also, in a previous study (10), we suggested that ESR measurements by TEST 1 reflect inflammation better than those obtained by the Westergren method in patients with malignancy, autoimmune disease, or infection. TEST 1 values obtained at hospital $\mathrm{C}$ were lower than those measured with the corrected Westergren method. Lower TEST 1 values at hospital $\mathrm{C}$ might be caused by the delay in measurement resulting from transportation of samples from hospital A, to hospital B, and finally, to hospital C. All ESR analyses should be performed within $4 \mathrm{~h}$ from the time of collection according to ICSH and Clinical and Laboratory Standard Institute (CLSI) recommendation $(7,11)$.

Storage of samples in EDTA tubes at $4^{\circ} \mathrm{C}$ for up to $24 \mathrm{~h}$ caused a significant decrease $(18.7 \%)$ in ESR values. This 
Table 3 Reference ranges for ESR determined using the TEST 1 for men and women according to age group.

\begin{tabular}{|c|c|c|c|c|c|c|c|c|}
\hline \multirow[t]{2}{*}{ Age, years } & \multicolumn{4}{|l|}{ Men } & \multicolumn{4}{|c|}{ Women } \\
\hline & $\mathrm{n}$ & $\begin{array}{l}\text { Mean, } \\
\mathrm{mm} / \mathrm{h}\end{array}$ & $\begin{array}{l}\text { Lower limit } \\
(2.5 \%), \mathrm{mm} / \mathrm{h}\end{array}$ & $\begin{array}{l}\text { Upper limit } \\
(97.5 \%), \mathrm{mm} / \mathrm{h}\end{array}$ & $\mathrm{n}$ & $\begin{array}{l}\text { Mean, } \\
\mathrm{mm} / \mathrm{h}\end{array}$ & $\begin{array}{l}\text { Lower limit } \\
(2.5 \%), \mathrm{mm} / \mathrm{h}\end{array}$ & $\begin{array}{l}\text { Upper limit } \\
(97.5 \%), \mathrm{mm} / \mathrm{h}\end{array}$ \\
\hline $18-30$ & 20 & 4.7 & 2 & 10 & 23 & 8.7 & 2 & 18 \\
\hline $31-40$ & 25 & 3.9 & 2 & 8 & 23 & 10.2 & 2 & 19 \\
\hline $41-50$ & 28 & 5.1 & 2 & 10 & 24 & 9.3 & 2 & 16 \\
\hline $51-60$ & 21 & 4.9 & 2 & 9 & 22 & 9.3 & 2 & 17 \\
\hline$>60$ & 16 & 5.3 & 2 & 10 & 18 & 7.6 & 2 & 12 \\
\hline Total & 110 & 4.8 & 2 & 10 & 110 & 9.1 & 2 & 19 \\
\hline
\end{tabular}

Table 4 Quality control results with latex controls, using three different TEST 1 analyzers in three hospitals.

\begin{tabular}{|c|c|c|c|c|c|}
\hline Latex control & $\mathrm{n}^{\mathrm{a}}$ & $\begin{array}{l}\text { Expected mean } \\
\text { (range), } \mathrm{mm} / \mathrm{h}\end{array}$ & $\begin{array}{l}\text { Mean } \pm S D, \\
\mathrm{~mm} / \mathrm{h}\end{array}$ & $\mathrm{CV}, \%$ & Bias, \% \\
\hline \multicolumn{6}{|l|}{ Level 1} \\
\hline Hospital A & 16 & $5(4-6)$ & $4.8 \pm 0.7$ & 14.4 & -4.0 \\
\hline Hospital B & 16 & $5(4-6)$ & $5.1 \pm 0.5$ & 9.8 & 2.0 \\
\hline Hospital C & 11 & $5(4-6)$ & $5.0 \pm 0.0$ & 0 & 0 \\
\hline \multicolumn{6}{|l|}{ Level 2} \\
\hline Hospital A & 16 & $23(20-26)$ & $24.1 \pm 2.2$ & 9.1 & 4.8 \\
\hline Hospital B & 16 & $23(20-26)$ & $25.0 \pm 1.4$ & 5.7 & 8.7 \\
\hline Hospital C & 11 & $23(20-26)$ & $25.0 \pm 0.9$ & 3.6 & 8.7 \\
\hline \multicolumn{6}{|l|}{ Level 3} \\
\hline Hospital A & 16 & $63(54-72)$ & $66.1 \pm 6.0$ & 9.1 & 4.9 \\
\hline Hospital B & 16 & $63(54-72)$ & $66.5 \pm 2.7$ & 4.1 & 5.6 \\
\hline Hospital C & 11 & $63(54-72)$ & $66.8 \pm 1.8$ & 2.7 & 6.0 \\
\hline
\end{tabular}

${ }^{\text {a}}$ Measured once a day.

decrease is greater than that (a decrease of 4.1\%) reported by Padro-Miquel and Fuentes-Arderiu (12), but is in agreement with the drop of $20.9 \%$ reported by Plebani and coworkers (3). CLSI recommendations are that the test should be run within $4 \mathrm{~h}$ if blood samples are left at room temperature or within $12 \mathrm{~h}$ if they are stored at $4^{\circ} \mathrm{C}(11)$.

The reference range data were analyzed using non-parametric statistics because ESR values did not show a true Gaussian distribution. In the present study, there was no increase in ESR with respect to age. The reference values of the present study were similar to those obtained in a study of Koreans (2-19 mm/h in men, 2-26 mm/h in women) (13), and lower than those in Italians $(2-28 \mathrm{~mm} / \mathrm{h}$ in men and 2-37 mm/h in women, aged $15-50$ years) (14). Differences in the reference population, such as race or region might be the cause of difference in the reference values (15).

TEST 1 values obtained from three hospitals in the accuracy study showed significant variation with respect to transport time. Blood samples showing significant decrease in ESR values with transport time are not suitable for interlaboratory proficiency testing. Latex control materials could be used for inter-laboratory proficiency testing because of satisfactory inter-assay precision.

In conclusion, TEST 1 ESR results showed good precision and good correlation with Westergren ESR data. Our results, obtained with latex control materials demonstrate that the TEST 1 QC for the measurement of ESR is reliable, and the latex control materials are valuable for inter-laboratory proficiency testing.

\section{Acknowledgements}

This research was supported by Basic Science Research Program through the National Research Foundation of Korea (NRF) funded by the Ministry of Education, Science and Technology (20090063258). We wish to thank members of the Jinsung Meditech (Seoul, Korea) for their technical support.

\section{Conflict of interest statement}

Authors' conflict of interest disclosure: The authors stated that there are no conflicts of interest regarding the publication of this article.

Research funding: None declared.

Employment or leadership: None declared.

Honorarium: None declared.

\section{References}

1. Plebani M, Piva E. Erythrocyte sedimentation rate: use of fresh blood for quality control. Am J Clin Pathol 2002;117:621-6.

2. Westergren A. The technique of the red cell sedimentation reaction. Am Rev Tuberc 1926;14:94-101. 
3. Plebani M, De Toni S, Sanzari MC, Bernardi D, Stockreiter E. The TEST 1 automated system: a new method for measuring the erythrocyte sedimentation rate. Am J Clin Pathol 1998;110: 334-40.

4. Bull BS. Quality assurance strategies. In: Koepke JA, editor. Practical Laboratory Hematology. New York, NY: Churchill Livingstone, 1991.

5. Giavarina D, Capuzzo S, Cauduro F, Carta M, Soffiati G. Internal quality control for erythrocyte sedimentation rate measured by TEST-1 analyzer. Clin Lab 2002;48:459-62.

6. Piva E, Pajola R, Temporin V, Plebani M. A new turbidimetric standard to improve the quality assurance of the erythrocyte sedimentation rate measurement. Clin Biochem 2007;40:491-5.

7. International Council for Standardization in Haematology (Expert Panel on Blood Rheology). ICSH recommendations for measurement of erythrocyte sedimentation rate. J Clin Pathol 1993;46:198-203.

8. Romero A, Munoz M, Ramirez G. Length of sedimentation reaction in blood: a comparison of the test 1 ESR system with the ICSH reference method and the sedisystem 15. Clin Chem Lab Med 2003;41:232-7.

9. Fabry TL. Mechanism of erythrocyte aggregation and sedimentation. Blood 1987;70:1572-6.

10. Cha CH, Park CJ, Cha YJ, Kim HK, Kim DH, Honghoon, et al. Erythrocyte sedimentation rate measurements by TEST 1 better reflect inflammation than do those by the Westergren method in patients with malignancy, autoimmune disease, or infection. Am J Clin Pathol 2009;131:189-94.

11. Clinical and Laboratory Standards Institute. Reference and selected procedure for the erythrocyte sedimentation rate (ESR) test; Approved standard, 4th ed. H2-A4. Villanova, PA: CLSI, 2000.

12. Padro-Miquel A, Fuentes-Arderiu X. Quality control strategy to verify day-to-day imprecision of length of blood sedimentation reaction measurements with the TEST-1 analyzer. Clin Chem Lab Med 2007;45:930-1.

13. Lee BH, Choi HJ, Gee MS, Lee KK, Park HS. Basic evaluation and reference range assessment of TEST 1 for the automated erythrocyte sedimentation rate. J Clin Pathol Quality Control 2002;24:167-72.

14. Piva E, Sanzari MC, Servidio G, Plebani M. Length of sedimentation reaction in undiluted blood (erythrocyte sedimentation rate): variations with sex and age and reference limits. Clin Chem Lab Med 2005;39:451-4.

15. Clinical and Laboratory Standards Institute. Defining, establishing, and verifying reference intervals in the clinical laboratory; approved guideline, 3rd ed. C28-A3. Villanova, PA: CLSI, 2008. 